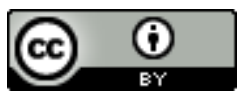

\title{
APRENDIZAGEM TECNOLÓGICA ATIVA
}

\author{
ACTIVE TECHNOLOGICAL LEARNING \\ APRENDIZAJE TECNOLÓGICO ACTIVO
}

\begin{abstract}
RESUMO: As metodologias ativas e as Tecnologias Digitais da Informação e Comunicação (TDIC) na educação estão cada vez mais presentes nas práticas pedagógicas. Uma ampla literatura científica destaca os impactos positivos na aprendizagem de ambos os elementos. No entanto, o número de professores que fazem o uso conjugado e simultâneo dessas ainda é baixo. Nesse sentido, este artigo descreve um novo paradigma de aprendizagem, conhecido como Aprendizagem Tecnológica Ativa (ATA), que é apoiado pelo uso combinado das tecnologias digitais e das metodologias ativas. Para isso, realizou-se uma pesquisa qualitativa considerando uma abordagem descritiva, interpretativa e dedutiva, possibilitando compreender os fenômenos dentro de seu contexto, descobrindo ligações entre conceitos, bem como determinando características do modelo da aprendizagem tecnológica ativa, utilizando o corpus latente de conteúdo. Os resultados desta pesquisa apontam que o modelo proposto pode ajudar a refletir sobre o uso das TDIC articulada com as metodologias ativas, atendendo às necessidades de uma educação digital e ativa, centrada no aluno. Por fim, apresentam-se algumas aplicações encontradas na literatura, como uma maneira de propor alguns norteadores para sua utilização na Educação, em especial no Ensino de Química, de modo a aprimorar ainda mais a compreensão do modelo da Aprendizagem Tecnológica Ativa.
\end{abstract}

PALAVRAS-CHAVE: Tecnologias digitais. Metodologias ativas. Aprendizagem tecnológica ativa.

ABSTRACT: Active methodologies and Digital Information and Communication Technologies (DICT) in education are increasingly present in the pedagogical practices. A broad scientific literature highlights the positive impacts on learning of both elements. However, the number of teachers who make a combined and simultaneous use of them turns out to be low. In this sense, this paper describes a new paradigm of learning, known as Active Learning Technology (ALT), which is supported by the combined use of digital technologies and active methodologies. For this, a qualitative research was carried out considering a descriptive, interpretative and deductive approach, making possible to understand the phenomena within its context, discovering links between concepts, as well as determining characteristics of the active technological learning model, using the content latent corpus. The results of this research point out that the proposed model can help to reflect on the use of articulated DICT with the active methodologies, attending to the needs of a digital and active education, centered on the student. Finally, some applications found in the literature are presented as a way to propose some guiding principles for their use in Education, especially in Chemistry Teaching, in order to further improve the understanding of the Active Learning Technology model.

KEYWORDS: Digital technologies. Active methodologies. Active technological learning.

RESUMEN: Las metodologías activas y las Tecnologías Digitales de la Información y Comunicación (TDIC) en la educación están cada vez más presentes en las prácticas pedagógicas. Una amplia literatura científica destaca los impactos positivos en el aprendizaje de ambos elementos. Sin embargo, el número de profesores que hacen el uso conjugado y simultáneo de estas todavía es bajo. En este sentido, este artículo describe un nuevo paradigma de aprendizaje, conocido como Aprendizaje Tecnológico Activo (ATA), que es apoyado por el uso combinado de las tecnologías digitales y de las metodologías activas. Para ello, se realizó una investigación cualitativa considerando un enfoque descriptivo, interpretativo y deductivo, posibilitando comprender los fenómenos dentro

Submetido em: 04/04/2018 - Aceito em: 18/04/2018 - Publicado em: 29/05/2018.

\begin{tabular}{l|l|l|l|l|l} 
(C) Rev. Inter. Educ. Sup. & Campinas, SP & v.4 & n.3 & p.580-609 & set./dez. 2018
\end{tabular}


de su contexto, descubriendo vínculos entre conceptos, así como determinando características del modelo del aprendizaje tecnológico activo, utilizando el corpus latente de contenido. Los resultados de esta investigación apuntan que el modelo propuesto puede ayudar a reflexionar sobre el uso de las TDIC articuladas con las metodologías activas, atendiendo a las necesidades de una educación digital y activa, centrada en el alumno. Por último, se presentan algunas aplicaciones encontradas en la literatura, como una manera de proponer algunos orientadores para su utilización en la Educación, en especial en la Enseñanza de Química, para perfeccionar aún más la comprensión del modelo del Aprendizaje Tecnológico Activo.

PALABRAS CLAVE: Tecnologías digitales. Metodologías activas. Aprendizaje tecnológico activo.

\section{INTRODUÇÃO}

O início do século XXI é descrito, sob diversas terminologias, como Era da Informação, Era Digital ou Sociedade do Conhecimento. Talvez estávamos ou estamos em um ponto da história em que os avanços tecnológicos, bem como as tendências econômica, demográfica e pedagógica, convergem e se reforçam mutuamente para criar um impulso que resulte em mudanças aceleradas nos próximos anos.

Nesse contexto, a necessidade de mudanças nas práticas pedagógicas está cada vez mais emergente. Se estas práticas não são renovadas, os métodos, processos e conteúdos educacionais que conhecemos (e admiramos) se tornarão irrelevantes porque deixarão de atender a demanda do seu contexto. Acredita-se que a manutenção de práticas consideradas obsoletas têm contribuído para um ensino centrado no professor, na qual tem distanciado os alunos do processo de construção de seu conhecimento. Dados interessantes divulgados pela pesquisa sobre mensuração de inovação na educação (OCDE, 2014), após pesquisar 34 países num intervalo entre 2000 a 2011, revelam que os professores têm inovado bastante em suas práticas pedagógicas. Contudo, no relatório mais recente (OCDE, 2017), destaca que o Brasil tem jovens professores que enfrentam condições de trabalho menos favoráveis, salários baixos, turmas maiores e podem ter menos oportunidades de realizar outras atividades. É observado também que a falta de qualificação dos professores (muitos destes "apegados" exclusivamente aos denominados métodos tradicionais de ensino) tem dificultado sua adoção em relação ao uso de diferentes metodologias de ensino.

Indubitavelmente a formação do professor (mediador, facilitador, formador) influencia em como este exerce sua prática pedagógica. O professor deve assumir uma atitude flexível ante as estratégias didáticas e de avaliação tanto no momento de organização e planejamento, como no processo de desenvolvimento, em virtude da imprevisibilidade e incerteza, e na tomada de decisão que há de ter em sua prática. Tradicionalmente, as salas de aula foram projetadas para satisfazer às necessidades dos professores (sua disposição, formato, estrutura, organização etc.). É preciso repensar a sala de aula. Observa-se que há algo essencialmente errado na escola como ela existe hoje. À medida que o tempo passa, nossos alunos, que deveriam estar cada vez mais envolvidos no processo de aprendizado, estão cada vez mais

\begin{tabular}{|l|c|c|c|c|c|}
\hline (C) Rev. Inter. Educ. Sup. & Campinas, SP & v.4 & n.3 & p.580-609 & set./dez. 2018 \\
\hline
\end{tabular}


distantes. É preciso centrar a aprendizagem no aluno. Por décadas a educação era centrada no que o professor transmitia para o aluno. Depois, passamos por um período de descoberta das tecnologias na educação.

Destarte, tornou-se então um desafio para professores e alunos, assim como para escolas, instituições de ensino superior e empresas adaptarem-se à complexidade dessas mudanças. Um novo perfil tem sido observado nas escolas e universidades no Brasil em que o professor deixa de ser o "transmissor do saber" e passa a ser o facilitador e mediador do conhecimento e os alunos deixam de ser receptores passivos de informações e atuam como colaboradores e participantes na construção coletiva do conhecimento. É nesse contexto que as tecnologias e as metodologias ativas têm crescido e se destacado no processo da construção do conhecimento. Em termos de produção na forma de artigos, o aumento (ainda) não é significativo em algumas áreas, por exemplo no Ensino de Química, com presenças esparsas em algumas revistas. Em outras áreas, como a pedagogia, a produção de artigos é muito mais pronunciada.

Considerando o elevado número de trabalhos na área de tecnologias e o aumento relevante das publicações envolvendo as metodologias ativas, o objetivo deste estudo é apresentar e explorar o modelo da Aprendizagem Tecnológica Ativa, destacando algumas aplicações no Ensino da Química. Para conseguir isso, primeiro elucidamos sobre as tecnologias na educação, tomando como referência pesquisas recentes. Em seguida, apresentamos e discutimos os referenciais teóricos envolvendo as metodologias ativas, que relacionadas com as tecnologias digitais da informação e comunicação postulam o modelo da Aprendizagem Tecnológica Ativa. Finalizamos com a apresentação de alguns resultados de pesquisas que apresentam características do modelo da Aprendizagem Tecnológica Ativa no Ensino de Química, no intuito de fornecer subsídios aos professores e estudantes (futuros professores) que buscam inovar em sua prática pedagógica.

\section{TECNOLOGIAS NA EDUCAÇÃO}

A adoção das Tecnologias Digitais de Informação e Comunicação (TDIC) no processo de ensino e aprendizagem no ensino básico e superior, por vezes, tem sido contraditório entre os docentes. Muitos professores, ao reconhecerem seu valor no processo de construção do conhecimento experimentam dificuldades na incorporação de sua prática pedagógica. No cenário atual, o uso de tecnologias digitais é um componente central da maior parte das formas de ofertas e práticas educacionais contemporâneas (SELWYN, 2017). A tecnologia digital tem tido claramente um impacto em muitas áreas da sociedade, sendo muito comum o emprego das TDIC voltadas para as práticas pedagógicas. Seu uso promove o aprendizado, facilita a interação e estimula os alunos a uma aprendizagem significativa.

\begin{tabular}{|l|c|c|c|c|c} 
(C) Rev. Inter. Educ. Sup. & Campinas, SP & v.4 & n.3 & p.580-609 & set./dez. 2018 \\
\hline
\end{tabular}




\section{IIII WW

As tecnologias digitais (móveis, conectadas, leves e ubíquas) não são apenas um recurso para o ensino, são também eixos estruturantes de uma aprendizagem criativa, crítica, personalizada e compartilhada. Elas trazem inúmeros problemas, desafios, distorções e dependências que devem ser parte do processo de ensino e aprendizagem. Em relação aos problemas, é nocivo ignorar uma educação avessa a um mundo conectado.

O relatório de um estudo do Campus technology de 2017, realizado com 232 professores de diversas faculdades nos Estados Unidos, destaca o uso das tecnologias no ensino por esses docentes. O estudo apresenta uma visão geral do uso das tecnologias na educação, sendo considerado por $80 \%$ dos entrevistados como positivo (KELLY, 2017). Além disso, apresenta uma perspectiva das tecnologias que irão desaparecer e as que serão importantes na próxima década (Quadro 1).

Quadro 1. Perspectivas das Tecnologias na próxima década

\begin{tabular}{|c|c|}
\hline $\begin{array}{l}\text { Top } 10 \text { tecnologias que irão desaparecer na } \\
\text { próxima década }\end{array}$ & $\begin{array}{l}\text { Top } 10 \text { tecnologias que irão tornar-se } \\
\text { importante na educação na próxima década }\end{array}$ \\
\hline 1) Computadores e laptops & 1) Realidade aumentada/virtual \\
\hline 2) Telefones e fax & 2) Dispositivos móveis e apps \\
\hline 3) Impressoras, escâneres e copiadoras & 3) Impressoras/escâneres/modelagem em 3D \\
\hline 4) Retroprojetores & 4) Aprendizagem adaptativa e personalizada \\
\hline $\begin{array}{l}\text { 5) CDs e DVDs e seus “tocadores”; Quadro de } \\
\text { giz/quadro branco }\end{array}$ & 5) Vídeo e transmissão \\
\hline 6) Livros e folhetos impressos & $\begin{array}{l}\text { 6) Ferramentas de colaboração e mídia social; } \\
\text { Internet das coisas e vestíveis }\end{array}$ \\
\hline $\begin{array}{l}\text { 7) Sistemas de gerenciamento de aprendizagem } \\
\text { (LMS); Apresentações tradicionais }\end{array}$ & $\begin{array}{l}\text { 7) Próxima geração de sistemas de } \\
\text { gerenciamento de aprendizagem (LMS) }\end{array}$ \\
\hline 8) Laboratórios informáticos & 8) Audio/videoconferência \\
\hline 9) Projetores não interativos & $\begin{array}{l}\text { 9) Ferramentas baseadas na nuvem; projetores e } \\
\text { quadros brancos interativos }\end{array}$ \\
\hline 10) Clickers & 10) Internet livre, rápida e segura \\
\hline
\end{tabular}

Fonte: Adaptado de Kelly (2017).

Muitas dessas tecnologias propostas para a próxima década já são conhecidas pelos pesquisadores no Brasil, porém poucas têm sido utilizadas nas práticas docentes, principalmente no Ensino de Química. Tal fato corrobora com a pesquisa recente de Reis, Leite e Leão (2017) sobre a apropriação das tecnologias da informação e comunicação (TIC) no ensino de ciências (Ensino de Química). Os autores realizaram uma revisão sistemática no período de 2007 a 2016 constando que poucos trabalhos foram desenvolvidos com interesse nas estratégias de uso das TIC. A maioria dos trabalhos publicados estavam focados no interesse pela funcionalidade das TIC e no interesse no uso das TIC, ou seja, as produções estavam empenhadas mais na utilização de algum material suportado pelas TIC, sem a preocupação de quem (o professor) irá utilizar ou como será essa utilização (qual estratégia). Nesse contexto, é mister mais pesquisas sobre estratégias de uso das TIC em sala de aula, investigando como elas desempenham papel importante na construção de conhecimento.

\begin{tabular}{l|l|l|l|l|l} 
(C) Rev. Inter. Educ. Sup. & Campinas, SP & v.4 & n.3 & p.580-609 & set./dez. 2018 \\
\hline
\end{tabular}




\section{METODOLOGIAS ATIVAS}

Partindo do pressuposto que as metodologias ativas não são novidades, elas têm se destacado refletindo sobre o papel do professor e do aluno no processo de ensino e aprendizagem, buscando provocar mudanças nas práticas em sala de aula que estão, por muitas vezes, enraizadas no modelo tradicional de ensino. A educação tradicional envolve a disseminação de informações diretamente do professor para o aluno. Este ambiente de aprendizagem passivo não é propício para a multiplicidade de estilos de aprendizagem (COOREY, 2016). Dewey (1950) já destacava a importância do aluno ativo na construção de seu conhecimento e da necessidade em superar a tradicional aula expositiva, cuja finalidade é a reprodução e a memorização do conteúdo de ensino. Esse protagonismo do aluno é também descrito nos Parâmetros Curriculares Nacionais (PCN) e corrobora para a consolidação dos quatro pilares essenciais da educação: o aprender a aprender, o aprender a fazer, o aprender a viver e a conviver e o aprender a ser (BRASIL, 2002).

A palavra Metodologia tem registro na língua portuguesa desde 1858. Etimologicamente a metodologia advém do grego, a partir dos termos: metá (atrás, em seguida, através); hodós (caminho); e logos (ciência, arte, exposição cabal, tratamento sistemático de um tema) (HOUSSAIS, 2001). Metodologia pode ser compreendida como tratado, disposição ou ordenamento sobre o caminho através do qual se busca, por exemplo, um dado objetivo de ensino ou mesmo uma finalidade educativa (ARAÚJO, 2015). Já a Aprendizagem Ativa, em oposição à aprendizagem passiva, bancária, baseada na transmissão de informação, o aluno assume uma postura mais ativa, na qual ele resolve problemas, desenvolve projetos e, com isto, cria oportunidades para a construção de conhecimento. Segundo Barbosa e Moura (2013, p. 55) a "aprendizagem ativa ocorre quando o aluno interage com o assunto em estudo (ouvindo, falando, perguntando, discutindo, fazendo e ensinando) sendo estimulado a construir o conhecimento ao invés de recebê-lo de forma passiva do professor". Em um ambiente de aprendizagem ativa, o professor atua como orientador, supervisor, facilitador do processo de aprendizagem, e não apenas como fonte única de informação e conhecimento. Dessa maneira, o aprendiz precisa ser um participante ativo para que ocorra a aprendizagem.

É importante destacar que as terminologias metodologia ou aprendizagem ativa variam dependendo de qual literatura tomamos como referência. Em muitos casos o termo metodologia ativa tem sido mais utilizado para referir-se a "estratégias pedagógicas que colocam o foco do processo de ensino e aprendizagem no aprendiz, contrastando com a abordagem pedagógica do ensino tradicional, centrada no professor, que transmite informação aos alunos" (VALENTE; ALMEIDA; GERALDINI, 2017, p. 463). Já o termo aprendizagem ativa é utilizado para "para caracterizar situações de aprendizagem em que o aluno é ativo" (VALENTE; ALMEIDA; GERALDINI, 2017, p. 463). Atribui-se esta caracterização devido ao fato de trabalhos em língua inglesa utilizarem o termo Active 


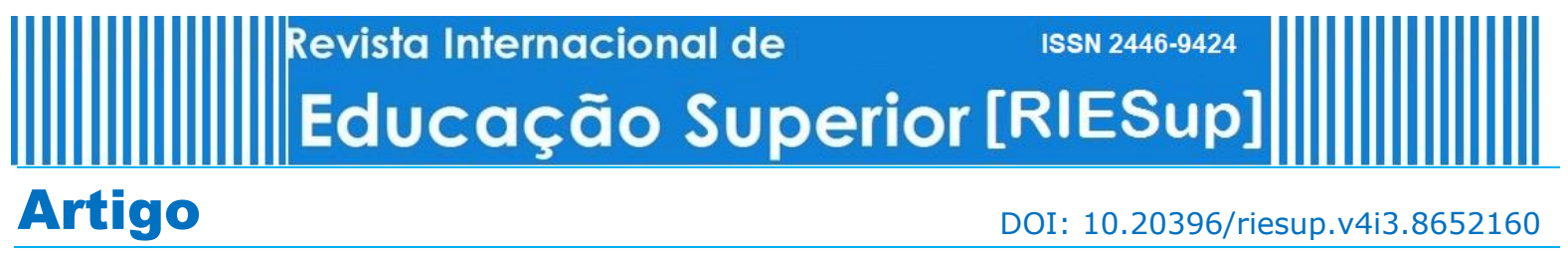

Learning, o que tem sido traduzido literalmente como aprendizagem ativa.

Dewey (1950), Bruner (1976), Piaget (2006), Vygotsky (1998) Rogers (1973), Ausubel et al. (1980), Freire (1996), entre tantos outros e de forma diferente, têm mostrado como cada pessoa (criança ou adulto) aprende de forma ativa, a partir do contexto em que se encontra, do que lhe é significativo, relevante e próximo ao nível de competências que possui. Todos esses autores questionam também o modelo escolar de transmissão e avaliação uniforme de informação para todos os alunos. Ademais, em livros, artigos, palestras, apresentações, são amplamente enfatizados que os alunos lembram 10\% do que ouvem, 20\% do que leem e essas percentagens de retenções aumentam em múltiplos de 10 dependendo do tipo de metodologia aplicada (MASTERS, 2013). Tem sido atribuído concomitantemente ao National Training Laboratories (NTL) e a Edgar Dale a construção da Pirâmide da Aprendizagem (Figura 1), embora esta Pirâmide tenha sido modificada ao longo das décadas (MASTERS, 2013), ela suscita a ideia de como os alunos aprendem. Um importante princípio da aprendizagem é que as pessoas aprendem melhor quando estão ativamente envolvidas no processo de aprendizagem. Quanto "mais baixo na pirâmide" o aluno está, mais ele aprende (DALE, 1969).

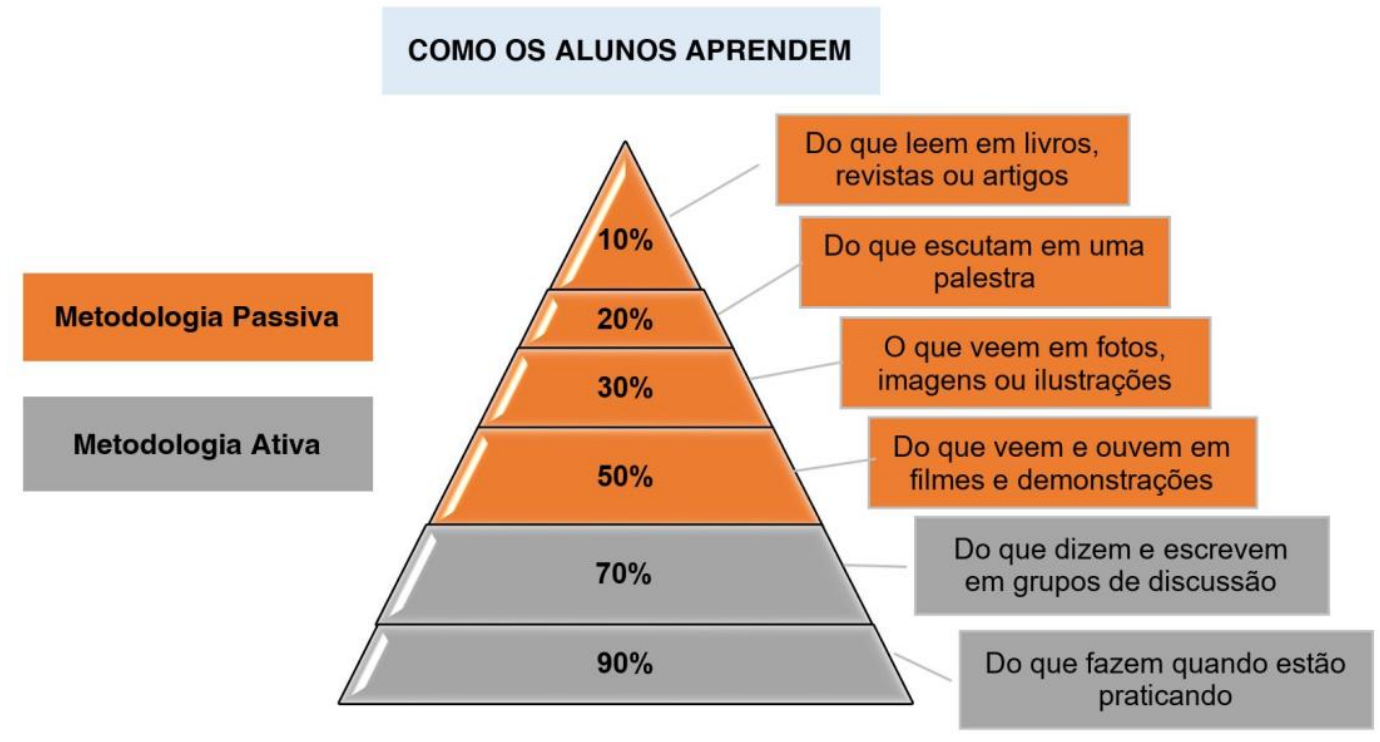

Figura 1. Pirâmide da Aprendizagem

Fonte: Adaptado de Dale (1969).

A Metodologia Ativa é uma estratégia que coloca os estudantes como principais agentes de seu aprendizado. Nela, o estímulo à crítica e reflexão é incentivada pelo professor que conduz a aula, mas o centro desse processo está no aluno. A transição de ambientes de aprendizado passivo para ativo está se tornando mais comum no mundo acadêmico (COOREY, 2016). As metodologias ativas dão ênfase ao papel protagonista do aluno, ao seu envolvimento direto, participativo e reflexivo em todas as etapas do processo, experimentando, desenhando, 
criando, com orientação do professor.

$\mathrm{Na}$ literatura encontramos algumas definições para Metodologia Ativa. Uma delas diz que a metodologia ativa consiste em tirar o foco da transferência de informações, estimulando a busca por conhecimento de forma autônoma. Ela também pode ser definida como o conjunto de atividades que ocupa o estudante a fazer algo ao mesmo tempo em que deve pensar sobre o que está fazendo (MEYERS; JONES, 1993), tendo o aluno como sujeito que promove a sua própria aprendizagem (ativa). Para Leite (2017a, p. 1) as metodologias ativas "possibilitam a valorização da formação crítica e reflexiva do estudante que participa da construção de seu conhecimento, no processo de ensino e aprendizagem, favorecendo sua autonomia". Nesse sentido, as metodologias ativas sugerem que o aluno busque o conteúdo, pesquise e encontre soluções para os problemas que se deparam e dessa forma aprendam a selecionar suas respostas. Elas geram interações entre docentes e estudantes nas atividades acadêmicas, de modo que não haja um único detentor pleno e absoluto do conhecimento. Mitre e colaboradores (2008, p. 2135) destacam que "as metodologias ativas estão alicerçadas em um princípio teórico significativo: a autonomia”. Segundo os autores as metodologias ativas utilizam "a problematização como estratégia de ensino e aprendizagem, com o objetivo de alcançar e motivar o discente, pois diante do problema, ele se detém, examina, reflete, relaciona a sua história e passa a ressignificar suas descobertas" (MITRE et al., 2008, p. 2135). Para Gaeta e Masetto (2010, s.p.), metodologias ativas "são situações de aprendizagem planejadas pelo professor em parceria com os alunos que provocam e incentivam a participação, postura ativa e crítica frente à aprendizagem”. Na aplicação da Metodologia Ativa, o estudante é exposto a problemas ou desafios em que as soluções requerem identificação das principais variáveis intervenientes.

Quando o aluno lê, escreve, questiona, discute, resolve problemas, ele se envolve ativamente no processo de aprendizagem. Dessa maneira, estratégias que promovem aprendizagem ativa podem ser definidas como sendo atividades que ocupam o aluno em fazer alguma coisa e, ao mesmo tempo, o leva a pensar sobre as coisas que está fazendo (BONWELL; EISON, 1991; SILBERMAN, 1996). Paiva et al. (2016) identificam diversas estratégias de aplicação das metodologias ativas, desde as amplamente discutidas na literatura, bem como as que têm poucas referências sobre o tema. Os autores relatam 22 diferentes tipos de operacionalização de metodologias ativas. Diante disso, a diversidade de propostas que apresentam princípios norteados por metodologias ativas é bastante significativa na educação, essas metodologias provocam os alunos a assumirem uma posição de maior responsabilidade na condução do seu processo de aprendizagem, passando a serem intensamente utilizadas na educação, algumas destas são: método do caso, sala de aula invertida (SAI), Instrução por Pares (Peer Instruction), Just-in-time Teaching (JiTT), Design Thinking (DT), aprendizagem baseada em problemas (PBL), projetos (PBL), equipes (TBL), games (GBL). Dessas propostas, neste artigo destacaremos três - envolvendo o ensino de química (SAI, Instruções por Pares e DT) - que são subsidiadas pelas TDIC.

\begin{tabular}{l|l|l|l|l|l}
\hline (c) Rev. Inter. Educ. Sup. & Campinas, SP & v.4 & n.3 & p.580-609 & set./dez. 2018
\end{tabular}




\section{PERCURSO METODOLÓGICO}

Segundo Thiollent (2005) a metodologia é o item que orienta o processo de investigação na tomada de decisões, nas hipóteses e nas técnicas da pesquisa. Demo (2006) destaca que a metodologia problematiza criticamente, além de mostrar os caminhos do processo, indagando os limites da ciência em conhecer e intervir em uma determinada realidade. Com base nisso, esta pesquisa, de natureza qualitativa, abrange uma abordagem descritiva e interpretativa, no qual o ambiente natural constitui uma fonte direta de dados e atribui ao investigador o papel de instrumento principal de pesquisa (LUDKE; ANDRÉ, 1986). Ademais, a metodologia qualitativa permite a descrição, análise e avaliação dos dados de forma articulada e aprofundada. Além de ser adequada para compreender os fenômenos dentro de seu contexto, descobrindo ligações entre conceitos e comportamentos, e gerando e refinando a teoria (BRADLEY; CURRY; DEVERS, 2007). Ao optar por essa metodologia faz-se uma relação direta ao paradigma interpretativo realizando-se também uma abordagem dedutiva para filtrar conceitos, indicadores, categorias e implicações da literatura. Como observado por Bradley, Curry e Devers (2007, p. 1763), uma análise dedutiva permite que "novas investigações se beneficiem e se baseiem em insights anteriores no campo", mas isso não exclui novas categorias. Este processo assegurou que as interpretações individuais da literatura fossem discutidas e coletivamente exploradas em detalhe, antes de completar o processo dedutivo de determinar as características do modelo da aprendizagem tecnológica ativa.

A pesquisa foi realizada em quatro etapas: (i) Revisão da literatura sobre tecnologias e metodologias ativas. Nesta etapa buscou-se analisar o estágio atual da contribuição acadêmica em torno das tecnologias digitais e das metodologias ativas, que serviram como aporte teórico-metodológico para a conceituação da aprendizagem tecnológica ativa; (ii) Proposição do modelo explicativo da aprendizagem tecnológica ativa. Elucidam-se nesta etapa o conceito e as características do modelo proposto (intrinsecamente relacionado à fase anterior), bem como os pilares que o ancoram. (iii) Levantamento e análise de publicações envolvendo tecnologias e metodologias ativas no ensino de química. Considerando a natureza do material a ser analisado (artigos publicados em periódicos), optamos por utilizar o corpus latente sobre conteúdo. O corpus latente é um modelo de investigação que analisa informações contidas na Internet, extraindo-as a partir da análise da própria Internet, ou seja, sobre o conteúdo disponível (PINA; SOUZA; LEÃO, 2013). A partir do banco de dados do Google Acadêmico, pesquisamos artigos que envolvessem metodologias ativas, ensino de química e tecnologias. Para nossa análise extraímos a amostra utilizando as palavras-chaves "Metodologias Ativas e Química", "Ensino aprendizagem metodologias ativas", "Aprendizagem ativa na Química", "Tecnologias ativas no ensino de química", "Active Methodologies and Chemistry", "Teaching learning active methodologies", "Active learning in chemistry" e "Active Technologies in Chemistry Teaching". Segundo Pina e colaboradores (2013), o uso de amostras aleatórias ou representativas permite aplicar técnicas de análises 
estatísticas. A opção pela versão em língua inglesa e em língua portuguesa para a mesma palavra de busca se deu devido ao pressuposto de que um número superior de trabalhos estariam disponíveis em língua inglesa, embora, nosso olhar está focado nos trabalhos em língua portuguesa. (iv) Discussões sobre o modelo da aprendizagem tecnológica ativa no ensino de química. A escolha na área de ensino de química, deve-se as implicações de que é uma disciplina de difícil compreensão e abstrata (SOUZA; LEITE; LEITE, 2015) e que pouco motiva os alunos a aprenderem (SANTOS et al., 2013). Desse modo, o modelo da aprendizagem tecnológica ativa leva-nos a acreditar que existem diversas possibilidades deste modelo contribuir para o ensino desta matéria.

A partir da investigação obtida na primeira etapa da pesquisa, propõe-se o modelo da aprendizagem tecnológica ativa (segunda etapa). Posteriormente, utilizando-se os dados obtidos no levantamento e na análise das publicações no corpus latente (terceira etapa), apresentam-se características do modelo no Ensino de Química (quarta etapa).

\section{APRENDIZAGEM TECNOLÓGICA ATIVA}

Dado o novo tipo de interações que a Internet facilita e medeia, parece-nos relevante considerar um modelo que dá suporte ao uso das metodologias ativas com as tecnologias, que tendo algumas características que se cruzam com as anteriormente referidas, possui outros aspectos distintivos, que colocam este tipo de modelo num patamar diferente. Assim, a partir do uso das TDIC com as Metodologias Ativas tem se observado um crescimento de novas práticas em sala de aula, facilitando o processo de ensino e aprendizagem, conduzindo à Aprendizagem Tecnológica Ativa (ATA).

A aprendizagem tecnológica ativa é um modelo explicativo sobre como ocorre a incorporação das tecnologias digitais às metodologias ativas no processo de ensino e aprendizagem visando melhorar a performance do aluno, que assume o protagonismo de sua aprendizagem, com autonomia e comprometimento. Segundo Beauchamp e Childress (1994) um modelo explicativo pode ser validado quando apresenta clareza, coerência, completude, simplicidade, poder explicativo, poder justificativo e poder resolutivo. Acrescentando-se, um modelo consiste na descrição de um sistema e/ou fenômeno que responde por algo já conhecido. $\mathrm{O}$ modelo da ATA propõe que o aluno tenha controle de sua aprendizagem, acessando conteúdos digitais (na nuvem) a qualquer momento, em qualquer lugar, em vez de depender exclusivamente do professor para seguir instruções. A ATA, num mundo conectado e digital, expressa-se por meio de modelos de ensino híbridos, com muitas possíveis combinações. A junção de metodologias ativas com as tecnologias trazem contribuições importantes para o desenho de soluções atuais para os aprendizes de hoje. Na aprendizagem tecnológica ativa os alunos podem se encontrar em um espaço on-line com o objetivo de falar, aprender, 
compartilhar informações ou colaborar em projetos. Eles mutuamente promovem uma participação proativa visando atender às necessidades dos outros.

A estrutura conceitual que fundamenta a aprendizagem tecnológica ativa baseia-se em abordagens construtivistas, construcionistas e conectivistas. A ATA endossa uma visão construtivista quando no final do processo evolutivo da aprendizagem, o indivíduo se torna autônomo, questionador, adaptativo e interativo no seu meio (PIAGET, 2006). No aspecto construcionista, a ATA pondera que o conhecimento é construído quando o indivíduo está engajado na construção de algo externo, quando ele "põe a mão na massa" (PAPERT, 1986), além da aprendizagem ocorrer na interação entre indivíduo e o mundo. Por fim, a relação conectivista é observada quando a habilidade de realizar distinções entre a informação importante e não importante resulta ser vital (SIEMENS, 2004), tendo como ponto de partida o indivíduo, explicando como ele se comunica e como aprende.

A composição da ATA constitui-se de cinco pilares que são considerados necessários para o processo de ensino e aprendizagem de forma ativa. Esses cinco pilares são: 1) O papel docente; 2) O protagonismo do aluno; 3) O suporte das tecnologias; 4) A aprendizagem; 5) A Avaliação. Em suma, cada pilar apresenta um grau de importância para a constituição de uma aprendizagem tecnológica ativa e são denominados de DATAV (Figura 2). A seguir descrevemos resumidamente cada pilar.

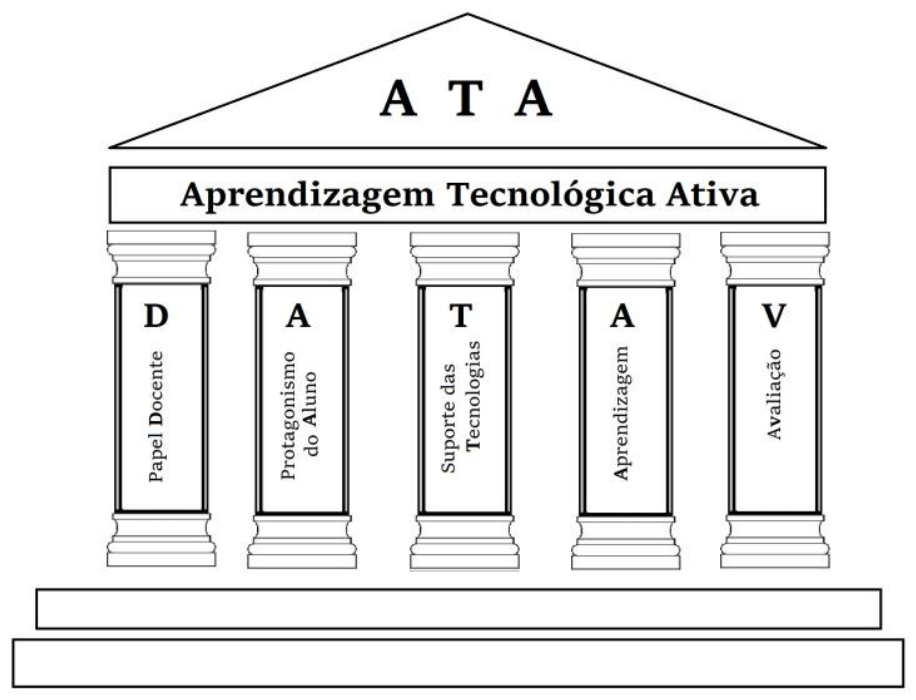

Figura 2. Pilares da ATA Fonte: Elaborado pelo autor

O primeiro pilar de sustentação da ATA refere-se ao papel Docente (D). Considerando que para que a ATA ocorra é preciso que o primeiro passo seja efetuado, e o professor é primordial nessa execução. Na ATA o professor atua como orientador, supervisor, facilitador do processo de aprendizagem, e não apenas como fonte única de informação e conhecimento.

\begin{tabular}{l|l|l|l|l|l}
\hline (c) Rev. Inter. Educ. Sup. & Campinas, SP & v.4 & n.3 & p.580-609 & set./dez. 2018 \\
\hline
\end{tabular}


Para que possa ajudar o aluno, o facilitador pedagógico, primeiramente, deverá possuir um entendimento claro da construção de conhecimento enquanto processo dinâmico e relacional, advindo da reflexão conjunta sobre o mundo real. Tal postura do professor configura-se como uma das características da metodologia ativa. Além disso, é preciso que os professores se dissociem de hierarquias e estejam dispostos a "cruzarem as linhas vermelhas" que dificultam seu novo papel. O professor ao utilizar as tecnologias com seus alunos pode ensinar a selecionar, analisar, criticar, comparar, avaliar, sintetizar, comunicar, informar. Esses são processos de pensamentos complexos que o professor mediador deve ensinar, para que seus alunos construam seu conhecimento. Cabe ressaltar, que o aluno em contato com o instrumento (computador, smartphone, laptop etc.) e a informação, não é conduzido ao conhecimento, ele vai “copiar e colar". É preciso que o professor seja o mediador desse processo, ele deve ajudar o aluno a decidir sobre a direção de sua aprendizagem e a escolher entre múltiplas opções para aprender os conceitos requeridos. Visto que as circunstâncias e as necessidades de aprendizagem dos alunos são tão diferentes quanto eles próprios, não existe uma única definição para o professor ideal. Porém, o professor deve ir além do ensino préformatado e ajude os alunos a realizarem seus trabalhos, ou seja, preencha a lacuna da orientação acadêmica (HORN; STAKER, 2015). O papel do professor, na ATA, aproxima-se de uma concepção do profissional que facilita a construção de significados por parte do aluno nas suas interpretações do mundo.

O segundo pilar se constitui do protagonismo do Aluno (A). Os alunos do século XXI estão entrando em um mundo conectado no qual necessitam de um sistema de ensino centrado neles. Para estimular o aluno a participar ativamente é preciso envolvê-lo e motivá-lo, de forma que interaja com o professor e com os demais alunos, tornando-o protagonista na construção de seu conhecimento. É preciso considerar nesse protagonismo dois elementos críticos da aprendizagem centrada no aluno, a possibilidade do aluno aprender de forma personalizada e aprender por competências (HORN; STAKER, 2015). O ensino personalizado refere-se que a aprendizagem é adaptada às necessidades particulares do estudante, ou seja, pode ocorrer onde, quando e como o aluno quiser. O segundo elemento crítico postula a ideia de que os "alunos devem demonstrar domínio de um determinado assunto" (HORN; STAKER, 2015, p. 9) antes de passar para o próximo, implicando em aspectos de perseverança e determinação, pois os estudantes têm de trabalhar nos problemas até que esses sejam resolvidos com sucesso. Se os alunos passam para um novo conceito sem compreender perfeitamente o anterior, isso cria lacunas em sua aprendizagem. $\mathrm{O}$ protagonismo do aluno o provoca a fazer as coisas, a colocar seu conhecimento em ação, a construir conhecimentos sobre os conteúdos envolvidos nas atividades que está realizando, provoca-o a pensar, a desenvolver estratégias cognitivas, a conceituar o que faz, não apenas como uma reprodução, mas com capacidade crítica e reflexiva sobre sua ação, de modo a apresentar feedbacks, interagindo com o professor e colegas, além de explorar atitudes e valores sociais e pessoais. Acrescenta-se a premissa de que o protagonismo do aluno evoca sua capacidade de tomar decisão a respeito de seu próprio aprendizado, ou seja, de sua

\begin{tabular}{|l|l|l|l|l|l}
\hline (C) Rev. Inter. Educ. Sup. & Campinas, SP & v.4 & n.3 & p.580-609 & set./dez. 2018 \\
\hline
\end{tabular}


autonomia. A capacidade de um aluno para desenvolver um plano de aprendizado pessoal, para encontrar recursos para o estudo em seu próprio ambiente pessoal/coletivo e/ou para decidir sozinho quando o progresso foi satisfatório, é imprescindível para uma ATA. Aceitar a idiossincrasia e a independência dos alunos como um recurso valioso é fundamental.

O terceiro pilar descreve o suporte das Tecnologias (T) para promover uma ATA. O desenvolvimento das TDIC promove a criação de novos cenários de aprendizagem e que são alternativos a educação formal para receber a informação, transformá-la em conhecimento e compartilhá-la, ou seja, conectar com outras pessoas. É indubitável que as plataformas educativas supõem um suporte suficientemente robusto e consistente para fazer possível a implementação dos princípios pedagógicos no processo de ensino e aprendizagem de forma inovadora e com êxito. Sabendo que o conhecimento é distribuído numa rede de conexões e que a aprendizagem consiste na capacidade de construir essas redes e circular nelas princípios do conectivismo (SIEMENS, 2004) - a aprendizagem tecnológica ativa faz uso do conhecimento que está na rede, ou seja, a ação de aprender utilizando as tecnologias pode ocorrer a partir da obtenção de informação externa ao conhecimento primário do indivíduo, resultado das conexões estabelecidas nas redes que fazem parte, por exemplo, aprender ativamente nas redes sociais. Destaca-se também que a Web 2.0 tem fornecido suporte ao uso das tecnologias pelos prosumidores, ou seja, pelos produtores e consumidores da informação (TOFFLER, 2007), de modo que apresenta potencial para mudar radicalmente a natureza do ensino e da aprendizagem e, através da criação de redes de aprendizagem controladas pelos prosumidores modificam o papel das tecnologias, consequentemente, na forma que se aprende. Diante do exposto, o professor deve saber as contribuições e limitações que cada recurso tecnológico apresenta, de modo que possa utilizá-lo nos projetos pedagógicos da disciplina e adequá-lo às estratégias de ensino, além de permitir a escolha consciente da tecnologia que melhor se adapta ao conteúdo a ser ensinado, promovendo uma ATA.

A ATA não se restringe a um único modelo de Aprendizagem (A), nela várias aprendizagens podem ser utilizadas e misturadas (blended). Embora seja fundamentada na aprendizagem ativa (MARTÍN, 2017), o quarto pilar da ATA apresenta quatro tipos de aprendizagem, não excludentes, tampouco únicas, que são comumente observadas: Aprendizagem individual (aquela que o aluno aprende de forma autônoma e pessoal), Aprendizagem colaborativa (em que favorece a colaboração entre pares, atingindo um determinado objetivo), Aprendizagem Social (em que o aluno aprende pela observação dos outros) e Aprendizagem Ubíqua (o aluno tem seu aprendizado ocorrendo a qualquer momento e em qualquer lugar), todas centradas no aluno. Descrevemos de maneira concisa cada uma delas.

$\checkmark$ Aprendizagem Individual (API): é qualquer mudança sistemática no comportamento individual ocorrida ao longo de certo período de tempo e que se completa quando o indivíduo atinge um padrão estável de comportamento (REIS, 1975). Segundo McWhinney (1963), a aprendizagem individual relaciona-se com a aptidão do

\begin{tabular}{l|l|l|l|l|l}
\hline (c) Rev. Inter. Educ. Sup. & Campinas, SP & v.4 & n.3 & p.580-609 & set./dez. 2018
\end{tabular}


indivíduo para a realização de uma dada tarefa. A API é derivada de condições acadêmicas (das relações com o professor e colegas) e estruturais (da organização das informações, dos detalhes estruturais e conceituais do que se aprende). A aprendizagem é um processo neural complexo, que leva à construção de memórias. Nós aprendemos lendo, ouvindo, errando, praticando, vivenciando e observando os outros. Inúmeras são as formas de aprender e cada pessoa se vê única nesse processo. Aprendemos intencionalmente e espontaneamente. Fleury e Fleury (2001, p. 192) afirmam que o processo de aprendizagem ocorre "primeiro no nível do indivíduo, carregado de emoções positivas ou negativas, através de caminhos diversos". Leite (2015, 2016) vem destacando o modelo de Aprendizagem 2.0 (aprender fazendo, aprender interatuando, aprender buscando e aprender compartilhando), cuja característica enriquece atividades baseadas na web, consequentemente, ressaltam a ATA. De certo, a forma como o indivíduo aprende tem sido discutida frequentemente em diversas teorias de aprendizagem;

$\checkmark$ Aprendizagem colaborativa (APC): considera que a troca de conhecimento pode levar à realização dos objetivos propostos. É preciso distinguir aprendizagem colaborativa de aprendizagem cooperativa (ONRUBIA; COLOMINA; ENGEL, 2010). Uma aprendizagem cooperativa é essencialmente um processo de divisão do trabalho, em que os participantes concordam em ajudar uns aos outros. Por sua vez, na APC, cada membro do grupo "contribui para resolver conjuntamente o problema" (ONRUBIA; COLOMINA; ENGEL, 2010, p. 210). A colaboração depende do estabelecimento de uma linguagem e de significados comuns no que diz respeito à tarefa, além de uma meta comum para o conjunto dos participantes. Nesse contexto, é preciso considerar as contribuições dos ambientes pessoais de aprendizagem que estão centrados na interação social e na colaboração, além de que o seu conceito está atribuído às condições de aprendizagem autônoma de educandos, baseado no uso de tecnologias a partir da Web 2.0 (LEITE, 2016). Ademais, o ambiente pessoal de aprendizagem representa "um passo importante para uma aprendizagem centrada nos alunos, com o uso das tecnologias" (LEITE, 2015, p. 165). A relação entre o ambiente pessoal e a aprendizagem colaborativa é evidenciada quando o conhecimento é visto como um produto social, e o processo educacional é facilitado pela interação social em um ambiente que propicia a colaboração, a cooperação e a avaliação. Com efeito, a APC contribui para o desenvolvimento da capacidade crítica por meio de debates, discussões e socialização das ideias com os demais colegas. Uma APC conhecida na literatura é a Aprendizagem Colaborativa Apoiada por Computador (CSCL), pois combina a noção de aprendizagem colaborativa com o potencial das TDIC para apoiála, ou seja, é ancorada com os pressupostos da ATA;

$\checkmark$ Aprendizagem social (APS): centra-se nas necessidades do indivíduo, é um conceito que se refere a uma aprendizagem que ocorre por meio de observação, conversação ou

\begin{tabular}{|l|l|l|l|l|l|}
\hline (C) Rev. Inter. Educ. Sup. & Campinas, SP & v.4 & n.3 & p.580-609 & set./dez. 2018 \\
\hline
\end{tabular}


questionamento. Nela aprendemos "de" e "com" os "especialistas", além de se desenvolver através de conversas, das redes sociais, e da Web 2.0. Bandura (1979) propôs que a APS pode ocorrer devido à observação dos outros. As pessoas aprendem coisas novas quando observam as ações dos outros, ou seja, os alunos adquirem novos comportamentos (aprendizado) através da observação dos outros. A APS (atualmente teoria social cognitiva) ocorre em contextos de interações estáveis, muitas vezes na Web em torno de problemas ou ações, nos quais há coisas a serem feitas, conhecidas, entendidas e dominadas. Ela é colaborativa, no sentido de que os participantes falam (escrevem etc.) sobre o que eles estão fazendo e tentam entender, conseguindo compreender conceitos, princípios e procedimentos por meio de suas interações e comunicações. Ao tentar criar algo, os alunos se deparam com situações e problemas que são novos para eles e não sabem como agir. Eles vão explorar e tentar resolver os problemas, buscando alternativas para isso. E quando o fazem, frequentemente compartilham on-line ou face a face com os pares envolvidos na mesma atividade. Quando compartilham on-line, geralmente em sítios, blogs, fóruns, redes sociais etc., outras pessoas podem também estar discutindo sobre o problema, sugerindo soluções e explicando-as, considerando os comentários e o feedback fornecido pelos demais colegas (ROMANCINI, 2015). Esses alunos estão em busca de informação sobre o que é válido do conteúdo em questão e podem encontrar por meio da ATA;

$\checkmark$ Aprendizagem Ubíqua (APU): tem como princípio permitir a qualquer um, aprender em qualquer lugar e a qualquer momento, possibilitada pelas tecnologias digitais e de conexão contínua, afetando diretamente a forma de ensinar e aprender. Nesse sentido, a APU se refere ao ambiente que permita que um dispositivo móvel acesse conteúdos de ensino e aprendizagem através de redes sem fio em qualquer local e a qualquer momento. Um ambiente de aprendizado ubíquo permite que os alunos aprendam com um PDA (Personal Digital Assistant), smartphone, Tablet, PC ou laptop, em situações internas, externas, individuais e em grupo. Segundo Yahya et al. (2010, p. 120), o objetivo da APU é "fornecer a informação certa no momento e local certos para acomodar o estilo de vida e de trabalho". Os autores destacam algumas características como: permanência (os estudantes nunca perdem seus trabalhos, o processo de aprendizagem é lembrado continuamente, a menos que seja removido), acessibilidade (acessam aos dados, vídeos, documentos de qualquer lugar, ou seja, as informações estão disponíveis sempre que os alunos precisarem usá-las), informação imediata (em qualquer momento o aluno pode ter acesso à informação), interatividade (os alunos podem interagir com colegas, professores e especialistas de forma eficiente e eficaz através de diferentes mídias), atividades (educativas) situadas (a aprendizagem se "integra" a vida diária, os problemas encontrados e o conhecimento exigido estão presentes de forma natural e autêntica). Assim como na APC, na APU o professor está presente, mas ele não é o detentor do conhecimento, sua função é de mediar a construção do conhecimento, utilizando as tecnologias digitais. Além disso, na APU o 
ponto mais importante é o acesso às redes e, a comunicação, pode ocorrer em qualquer tempo e hora, por meio de dispositivos móveis. A APU se dá sempre no "aqui e agora, sendo, por natureza, dispersa, casuística, o que pode levar muitos a negar que haja aí processos de aprendizagem" (SANTAELLA, 2014, p. 21). Ademais, a aprendizagem ocorre quando o aluno utiliza os dispositivos móveis conectados em rede, transformando a informação em aprendizagem (SANTAELLA, 2014). As características que a ubiquidade apresenta endossam sua importância na ATA.

Na ATA esses quatro tipos de aprendizagens podem ser observadas simultaneamente em uma proposta, dependendo do tipo de estratégia que o professor incorpore.

Por último, não menos importante, temos o pilar da Avaliação (V) que está presente na ATA. A avaliação desempenha um papel essencial para a educação, consiste em refletir, requer analisar seus resultados e tomar decisões em relação ao que fazer para que os alunos superem as suas dificuldades e avancem. Na ATA diversos tipos de avaliação podem ser observadas: classificatória, diagnóstica, formativa, somativa, autoavaliação etc. É pujante estabelecer que na ATA, uma avaliação formativa é fundamental para identificar as dificuldades dos alunos de modo a ajudá-los a descobrirem meios que lhes permitirão progredir em sua aprendizagem (HOFFMANN, 2014). Por outro lado, a avaliação na ATA deve ocorrer por meio da compreensão e mediação, ao invés da verificação e medição. A avaliação compreensiva e mediadora consiste em ampliar as possibilidades de aprender dos alunos a partir de um acompanhamento de ações desenvolvidas por eles nos ambientes digitais (na qual a aprendizagem está centrada neles). Ela auxilia os alunos a estudarem seus avanços (para os que conseguiram), mostrando ao mesmo tempo aqueles aspectos que ainda podem melhorar. O erro, neste caso, não é considerado como negativo, ele é construtivo, é parte no processo de uma aprendizagem ativa. Ademais, o processo de avaliação pode ocorrer de duas formas: avaliação formal (ocorre com data e horário pré-estabelecidos) ou avaliação informal (acontece sem tempo e espaço pré-estabelecidos), ambas possíveis na ATA. Outrossim, é preciso considerar que a aprendizagem colaborativa pode contribuir na avaliação em uma ATA, ao fornecer relacionamentos de tutoria por meio da interação de estudantes "avançados" (que apresentam nível de conhecimento aprofundado sobre um determinado conteúdo), "iniciantes" (aqueles que estão conhecendo o conteúdo ou apresentam nível de compreensão do conteúdo incipiente) e "intermediários" (que apresentam bom conhecimento sobre o conteúdo, em que podem auxiliar os estudantes "iniciantes" que apresentam dificuldades, contudo diante de uma complexidade do conteúdo necessitam da ajuda dos "avançados"), de modo que o aumento no desempenho das avaliações é fomentado por meio da troca de experiências e aprendizado coletivo.

Os pilares descritos acima, de forma concisa, sintetizam a complexidade da aprendizagem tecnológica ativa na Educação. Embora existam inúmeros benefícios associados a ela, os educadores devem estar cientes dos possíveis obstáculos. Para que os alunos se envolvam na

\begin{tabular}{l|l|l|l|l|l}
\hline (c) Rev. Inter. Educ. Sup. & Campinas, SP & v.4 & n.3 & p.580-609 & set./dez. 2018
\end{tabular}


ATA e maximizem os benefícios, os professores devem coordenar conscientemente a atividade de aprendizagem. A luz dessa discussão, considerando que o foco da ATA é a construção de conhecimento utilizando as tecnologias digitais por meio das metodologias ativas, encontramos algumas propostas que contemplam essa abordagem (etapa 3). Descrevemos na próxima seção uma breve análise na área do Ensino de Química.

\section{APRENDIZAGEM TECNOLÓGICA ATIVA NO ENSINO DE QUÍMICA}

A investigação utilizando o corpus latente sobre conteúdo forneceu trabalhos que abordavam as tecnologias e metodologias ativas no Ensino de Química. Embora o Google Acadêmico tenha um caráter infinito de dados para o corpus latente de conteúdo, ou seja, se realizarmos uma busca um período depois os resultados apresentados terão alta probabilidade de serem diferentes, no entanto as amostras obtidas, conforme Souza (2010), possibilitam uma análise representativa das produções sobre a ATA no Ensino de Química. Analisamos o corpus latente dos artigos em relação a seus objetivos, áreas de concentração e relatos de experiências, compreendendo suas contribuições. Realizou-se a leitura de seus resumos, considerando que estes apresentam uma boa forma de identificar os objetivos do trabalho. Quando essa informação não estava explícita no resumo, se fez necessário a leitura na íntegra do texto, possibilitando evidenciar as características da ATA.

\section{Sala de aula invertida no Ensino de Química}

O primeiro tipo de aprendizagem tecnológica ativa que destacamos é o modelo da sala de aula invertida (Flipped Classroom). A priori para discutirmos sobre a SAI é preciso diferenciá-la da aprendizagem invertida. Em poucas palavras, na sala de aula invertida, proposta pelos professores de química Bergmann e Sams (2016), o estudante faz em casa o que tradicionalmente fazia na sala de aula. A SAI significa uma mudança na maneira de ensinar, servindo como ponto de partida para pôr o professor e seus alunos no caminho de uma aprendizagem invertida (flipped learning). Ao inverter a sala de aula, o modo como o professor ensina evoca a aprendizagem invertida (MARTÍN, 2017). Segundo Martín (2017, p. 21) a aprendizagem invertida "consiste em criar um novo ambiente de relação entre professores e alunos em que mudam os papéis tradicionais e se inverte o protagonismo". A SAI é um tipo de Modelo de Rotação presente no ensino híbrido em que o aluno estuda um conteúdo didático em casa e a sala de aula é utilizada para a resolução de atividades, discussões sobre o conteúdo, entre outras propostas.

A SAI engloba toda uma série de metodologias baseadas na transmissão da informação a aprender por meios eletrônicos fora da sala de aula (MARTÍN, 2017). A informação que os alunos devem aprender se transmite em hipertextos e hipermídias com links a documentos, 
apresentações, vídeos e podcasts. Desse modo, se utiliza o tempo de aula para um diálogo bidirecional, em vez de desperdiçar todo o tempo da aula em um monólogo explicativo ininterrupto de informações que, por outro lado, os estudantes podem encontrar nos diferentes materiais didáticos (livros, vídeos, jogos, artigos etc.). A preparação dos alunos para a aula é "estimulada e encorajada de diferentes maneiras em cada um dos meios de comunicação descritos para chegar a uma aprendizagem invertida" (MARTíN, 2017, p. 21). A implementação de uma aprendizagem invertida implica enriquecer a comunicação bidirecional por meios virtuais, isto é, utilizando as TDIC, entre professores e alunos antes das aulas. Contudo, é necessário que o professor estabeleça um sistema eficaz de "comunicação bidirecional com seus alunos podendo obter informações muito valiosas e pertinentes sobre as dificuldades e reações de seus alunos" (MARTÍN, 2017, p. 91) quando se discute sobre os materiais propostos e na interação sobre o conteúdo em sala de aula.

A compreensão dos vários aspectos relacionados com a mudança no papel do professor na aprendizagem invertida é descrita por quatro pilares, denominados de FLIP (criados pela Flipped Learning Community Network). Estes pilares são:

1) Flexibilidade do ambiente de aprendizagem (F de Flexible environment). Neste pilar a aprendizagem invertida se adapta à variedade de metodologias à disposição do espaço de aprendizagem para discutir um conteúdo ou unidade;

2) Cultura da aprendizagem centrada no que aprende ( $\mathbf{L}$ de Learning culture). Neste pilar deve-se produzir uma quebra de paradigmas desde o modelo tradicional de ensino (centrado no protagonismo do professor que ensina) ao novo paradigma centrado no protagonismo dos que aprendem.

3) O uso intencional do conhecimento para aprender (I de Intentional). Os professores devem usar o conteúdo a ser aprendido para "alcançar a compreensão de ideias essenciais e do desenvolvimento dos alunos a longo prazo” (MARTín, 2017, p. 97). Os professores devem determinar o que deve ser ensinado e quais conceitos devem ser estudados.

4) Educador profissional (P de professional). Como já observado, o papel do professor é mais complexo que o que ele tinha no ensino dito tradicional. Segundo Martín (2017, p. 97) o professor "deixa de ser somente apresentador de informação e avaliador de sua assimilação". No tempo utilizado em sala de aula, o professor conduz os alunos, os guia, os observa e avalia seu trabalho, proporcionando-os feedback relevante no momento em que os alunos necessitam.

Implementar o modelo invertido supõe aprender a diagnosticar no momento os problemas dos estudantes para aprender e desenvolver soluções para a aula.

No semestre letivo de 2007-2008 Bergmann e Sams (2016) foram os primeiros divulgadores de algumas técnicas da SAI na Química, utilizando o vídeo como material para estudo prévio, com a vantagem de que cada aluno pode assisti-lo no seu ritmo, quantas vezes precisar. Eles

\begin{tabular}{l|l|l|l|l|l}
\hline (C) Rev. Inter. Educ. Sup. & Campinas, SP & v.4 & n.3 & p.580-609 & set./dez. 2018 \\
\hline
\end{tabular}


gravaram todas as aulas de química para esse semestre. A experiência serviu como incentivadora para que professores de Química buscassem aplicar a SAI em suas aulas. Os cinco pilares (DATAV) da ATA são contemplados na SAI, como observamos nos artigos analisados (etapa 3). A saber, em língua inglesa, encontramos inúmeras pesquisas utilizando a SAI como metodologia para o Ensino de Química. Desde comprovando a eficácia da SAI em turmas grandes (YESTREBSKY, 2015), seu impacto no desempenho e retenção dos alunos na disciplina de Química Geral (RYAN; REID, 2016) e nas notas dos alunos de Química Orgânica (CORMIER; VOISARD, 2018), bem como na avaliação de um Curso de Química Orgânica (MOORING; MITCHELL; BURROWS, 2016), de cursos de química no ensino superior (SEERY, 2015) e do Ensino Médio (SCHULTZ et al., 2014).

A primeira experiência tratando sobre a SAI no Ensino de Química, em língua portuguesa, observada no corpus latente foi descrita por Leite (2017b). O artigo apresenta um relato sobre a importância das contribuições da SAI na prática docente, embora pouco se tem discutido no Ensino de Química. O artigo sugere algumas possibilidades e contribuições que o uso da SAI no ensino de química pode ocasionar. Muitas dessas sugestões apresentam características da ATA, como a utilização de recursos didáticos digitais, pertinentes aos conteúdos e acessíveis a todos os estudantes. Para Leite (2017b, p. 1594) o "uso de softwares e hipermídias podem contribuir para a aprendizagem dos alunos". Sob o mesmo ponto de vista, o uso de hipertextos e podcasts com foco no conteúdo de química configuram-se como uma estratégia pertinente em termos educacionais e da ATA. Ademais, é destacado grande potencial do vídeo - assim como Bergmann e Sams (2016) utilizaram - na metodologia da SAI.

Outro trabalho em língua portuguesa sobre a SAI foi produzido por Chaparro (2016). Este trabalho não foi analisado na pesquisa de Leite (2017b), pois tratava-se de uma publicação em congressos e não era o foco de sua investigação. Chaparro (2016) aplicou a metodologia da SAI para o estudo de Modelos Atômicos no Ensino Médio, indicando que os resultados dessa proposta propiciou aos alunos uma aprendizagem colaborativa e significativa, corroborando com os pressupostos da ATA. É interessante destacar que as atividades propostas (uso de vídeos do youtube ${ }^{\circledR}$, hipermídias, simulações e animações) eram disponibilizadas em uma rede social, ou seja, a atividade possibilitou, por exemplo, a interação nas redes (característica da ATA). A autora destaca que uma das contribuições da SAI foi o incentivo à concentração e à leitura, relacionando ao fato dos alunos também se motivaram por terem familiaridade com as ferramentas usadas (recursos didáticos digitais, redes sociais etc.).

Melo e Sánchez (2017) relataram uma experiência em que analisaram as percepções dos alunos sobre a metodologia da SAI para o ensino de técnicas avançadas em laboratórios de resíduos. A pesquisa apresenta o uso do vídeo como uma ATA, considerando a utilidade e facilidade deste recurso, ocasionando em uma maior interação dos alunos com o professor e entre eles, e que a dedicação do professor na criação dos vídeos foi valorizada positivamente pelos alunos. É preciso destacar também que alguns alunos foram resistentes a

\begin{tabular}{l|l|l|l|l|l} 
(c) Rev. Inter. Educ. Sup. & Campinas, SP & v.4 & n.3 & p.580-609 & set./dez. 2018 \\
\hline
\end{tabular}


implementação deste modelo frente a uma aula mais "tradicional" (MELO; SÁNCHEZ, 2017). Os autores indicam que a SAI é uma alternativa para o ensino e aprendizagem do trabalho experimental e envolve alunos em sua própria aprendizagem, permitindo que eles interajam constantemente com seu ambiente educacional, resolvendo problemas e tomando decisões, corroborando com os fundamentos da ATA.

Para discutir o conteúdo de radioatividade com alunos do $3^{\circ}$ ano do ensino médio, LimaJúnior e colaboradores (2017) aplicaram a SAI na disciplina de Química. A estratégia utilizada para promover a ATA nas aulas deu-se por meio do uso de quizzes, vídeos e de uma wiki como ambiente virtual de aprendizagem. Segundo os autores (2017, p. 137) "houve uma participação mais ativa dos alunos nas atividades em sala de aula, os quais, ao lerem os textos presentes na plataforma on-line, assistirem às vídeo-aulas e responderem os quizzes, antes da aula presencial". Ademais, a SAI provocou nos alunos uma participação mais ativa, fazendo com que estes apresentassem colocações "mais fundamentadas, críticas e argumentativas nas discussões em sala de aula" (LIMA-JUNIOR et al., 2017, p. 137), além de obterem um desempenho superior a uma turma (do mesmo ano) que não utilizou a SAI durante a intervenção do conteúdo proposto.

\section{Instrução por Pares no Ensino de Química}

Apoiado em leituras pré-aula relacionadas ao tema proposto, o professor fomenta e medeia o debate entre os alunos, lançando questões conceituais baseadas nas dificuldades da turma. As aulas, assim, tornam-se direcionadas e efetivas, propiciando o auxílio mútuo entre os alunos na construção de seu conhecimento. Essa descrição de atividade é fundamentada pelo modelo Peer Instruction (PI) ou Instrução por pares, proposto por Eric Mazur (na década de 90). Esse modelo visa o entendimento e aplicabilidade dos conceitos, valendo-se da discussão entre os alunos. Entretanto, deve-se ter o cuidado com a tradução "instrução por pares", pois ela pode dar a falsa impressão de que os alunos deverão trabalhar, necessariamente, em duplas (pares), o que não é verdade, uma vez que podem ser formados (também) grupos de estudantes. Para obter uma melhor dinâmica de grupo, pequenos grupos (abaixo de seis) são comprovadamente mais eficazes (COOREY, 2016). Pequenos grupos impedem a passividade e são menos propensos a cair sob o domínio de alguns membros, como os grandes grupos geralmente experimentam.

Nessa metodologia exige-se que os alunos leiam, pensem e reflitam antes da aula (TOLEDO; LAGE, 2013). Com efeito, o professor pode dialogar com seus estudantes através do ambiente virtual de aprendizagem da disciplina, o que proporciona, também, um acompanhamento de todo o processo, característica de um ambiente baseado na ATA. A Instrução por Pares envolve os alunos durante as aulas, através de atividades que exigem que cada aluno aplique os conceitos básicos que estão sendo apresentados e depois explique esses conceitos aos seus colegas (CROUCH; MAZUR, 2001). Consiste em prover material de

\begin{tabular}{l|l|l|l|l|l}
\hline () Rev. Inter. Educ. Sup. & Campinas, SP & v.4 & n.3 & p.580-609 & set./dez. 2018
\end{tabular}


apoio de modo que o aluno possa estudar o conteúdo antes de frequentar a sala de aula. Com base no material estudado, o aluno responde um conjunto de questões, via um ambiente virtual de aprendizagem. O professor antes de ministrar a aula, verifica as questões mais problemáticas, que devem ser trabalhadas em sala de aula. A metodologia de aplicação da instrução por pares prevê, o uso da tecnologia para alcançar os objetivos, assim reforçando um dos pilares da ATA. Ademais, essa metodologia pressupõe que a aprendizagem seja conduzida também por meio da interação entre os próprios estudantes, outro atributo da ATA.

A instrução por pares pode ocorrer da seguinte maneira: Primeiro é importante que o aluno tenha estudado o conteúdo proposto antes de ir para a aula. Após a leitura prévia dos conteúdos, na aula o professor faz uma rápida exposição do tema (já estudado em casa), com duração de 7 a 10 minutos e aplica os testes conceituais (ConceptTest) sobre os conteúdos que estudaram por meio de softwares e aplicativos, em que o professor acessa instantaneamente o desempenho de cada aluno por meio do computador. Estes testes são respondidos via sistema de resposta interativo, tipo clickers, formulários (como os do Google Docs ou Monkey Survey) ou flashcards, de modo que a classe e o professor possam acompanhar o nível de compreensão sobre os conceitos em discussão. Antes de responderem ao teste, os alunos têm um ou dois minutos para pensar sobre a questão e formular suas próprias respostas. É importante que no primeiro momento os colegas não saibam as respostas uns dos outros para não serem mutuamente influenciados. Dessa forma é possível verificar as principais dificuldades e então realizar as devidas explicações sobre o tema da aula. ConcepTests apropriados são essenciais para o sucesso dessa metodologia (CROUCH; MAZUR, 2001). Eles devem ser elaborados para dar aos alunos a oportunidade de explorar conceitos importantes, em vez de testar esperteza ou memória, e expor dificuldades comuns com o material. É preciso destacar que a partir do nível de acertos e erros dos alunos, a aula adota diferentes rumos. Se o percentual de acerto for inferior a $30 \%$ o professor repete a exposição, apresentando outros elementos (não discutidos no início da aula). Se o percentual de acerto está entre $30 \%$ e $70 \%$, ocorre a Instrução por pares, ou seja, formam-se grupos de alunos que discutem o conteúdo abordado. A ideia é que eles cheguem a um consenso sobre a resposta correta. Este processo conduz os alunos a pensarem sobre os argumentos a serem desenvolvidos e permite que eles (assim como o professor) possam avaliar o nível de compreensão sobre os conceitos antes mesmo de terminar a aula. A partir disso é reaplicado o teste conceitual para avaliar o nível de entendimento dos estudantes e se o percentual de acerto for acima de 70\%, o professor faz uma explanação sobre as respostas, e posteriormente apresenta uma nova questão ou introduz um novo conteúdo (Figura 3). Salientamos que os cinco pilares da ATA (DATAV) estão explicitamente presentes nessas etapas. 


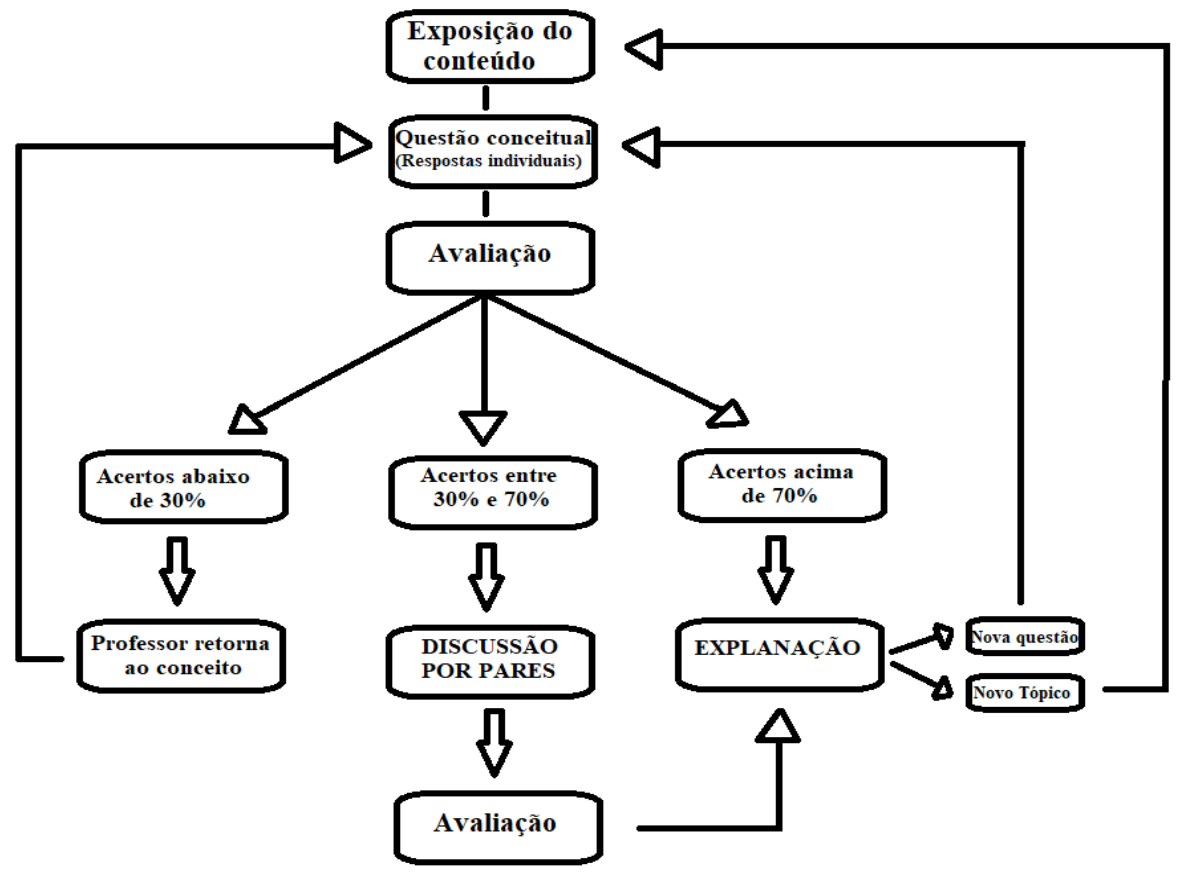

Figura 3. Etapas da Instrução por pares Fonte: Elaborado pelo autor

Resumindo, segundo Crouch e Mazur (2001), na instrução por pares o professor propõe questões baseadas nas respostas do aluno sobre sua leitura "pré-classe". O aluno reflete sobre essas questões, pratica resolução de exercícios individualmente. $O$ professor corrige as respostas do aluno. Este discute as suas ideias e responde questões com seus pares, pratica de novo a resolução de exercícios individualmente. Por fim, o professor novamente revisa as respostas e decide se é necessário mais explicações antes de mudar para o conceito seguinte. A instrução por pares promove a interação em sala de aula para envolver os alunos e abordar aspectos críticos da disciplina (ROCHA; LEMOS, 2014). Faz com que os alunos aprendam enquanto debatem entre si, provocados por perguntas conceituais (que podem ser de múltipla escolha), direcionadas para indicar as dificuldades dos alunos e promover no estudante uma oportunidade de pensar sobre conceitos desafiadores.

O primeiro relato da Instrução por pares no ensino de química, a partir de nosso levantamento no corpus latente foi em 2006, quando Golde, McCreary e Koeske (2006) avaliaram a aprendizagem dos alunos a partir da instrução por pares no laboratório de Química Geral. A atividade conduziu os alunos a descobrirem uma abordagem geral e eficaz para realizar atividades no laboratório, envolvendo-os na construção de seus próprios conhecimentos. Ademais, os autores indicam que melhorias foram observadas no desempenho dos estudantes, destacando a relação professor-aluno, permitindo a adoção "de uma abordagem baseada em pequenos grupos" (GOLDE; MCCREARY; KOESKE, 2006, p. 810), interação e trabalho coletivo, apresentando atributos da ATA. 
Passados dez anos, o primeiro trabalho (e único encontrado) em língua portuguesa sobre a instrução por pares no ensino de química foi publicado por Moraes, Carvalho e Neves (2016), que relatam os resultados de um estudo exploratório em quatro turmas de química, abordando o conteúdo de estequiometria. A experiência da instrução por pares, segundo os autores, com os alunos mostrou-se positiva, em que os alunos apresentaram engajamento e motivação com a proposta abordada em sala de aula (conforme os preceitos da ATA). Foi considerado como um método adequado para o ensino de química, permitindo aos alunos, "a elucidação de conceitos importantes e subjacentes" (MORAES; CARVALHO; NEVES, 2016, p. 1), além de proporcionar novas estratégias para o ensino de química.

Evidenciamos em nosso levantamento que em língua portuguesa, relacionado com a química, apenas um trabalho foi publicado. A falta de trabalhos sobre a instrução por pares no ensino de química indica a necessidade de mais pesquisas que relatem as contribuições desta metodologia. É notória sua relevância e quando incorporada a estratégias envolvendo a ATA, por certo resultará na autonomia do estudante (à medida que estuda e pesquisa sobre o conteúdo antes de ir para a aula), no aprendizado individual (estudando o assunto previamente) e coletivo (ao estudar e debater sua opinião e pensamentos com os demais colegas). Em vista disso, cabe ressaltar que a instrução por pares promove uma comunidade de aprendizagem colaborativa (um dos pilares da ATA), aumenta as habilidades de liderança e cria aprendentes para toda a vida.

\section{Design Thinking no Ensino de Química}

Por último, destacamos o Design Thinking (DT) que apresenta possibilidades de uma aprendizagem tecnológica ativa. O DT é um novo jeito de pensar e abordar problemas ou, dito de outra forma, um modelo de pensamento centrado nas pessoas. Pode ser uma abordagem que descentraliza a prática do design das mãos de profissionais especializados ao permitir que seus princípios sejam adotados por pessoas que atuam em áreas profissionais variadas (CAVALCANTI; FILATRO, 2016) ou uma metodologia para propor soluções criativas e inovadoras para problemas que utilizam a forma de pensar dos designers. Para Tim Brown, um dos maiores defensores do DT, é um modelo que "se baseia em nossa capacidade de sermos intuitivos, reconhecer padrões, desenvolver ideias que tenham significado emocional assim como funcional, nos expressar em mídias além de palavras ou símbolos" (BROWN, 2009, p.4). Na literatura encontramos algumas propostas para as etapas do DT na educação, que são basicamente semelhantes. A primeira descrita pelo Bootcamp Bootleg (D.SCHOOL, 2011) considera cinco etapas para sua execução: criar empatia (às vezes dividida em entender e observar), definir, idear, prototipar e testar. Outra proposta é da Ideo (2009) sendo apresentada no HCD Toolkit como ouvir, criar e entregar (do inglês Hear, Create e Deliver, formando o acrônimo HCD e de analogamente a Human Centered Design). Já o Design thinking para educadores (IDEO, 2013) propõe os seguintes passos: descoberta, 
interpretação, ideação, experimentação e evolução. Em alguns casos, esses passos são resumidos em imersão (descoberta e interpretação), ideação e prototipagem (experimentação e evolução).

Na educação o DT pode ser percebido em três aplicações (CAVALCANTI; FILATRO, 2016):

1) Como uma abordagem de inovação: Fundamentado na ideia de inovar, criar algo, reorganizar ideias ou melhoria de produtos, processos e serviços. Sem considerar, necessariamente, a aprendizagem que ocorre durante o processo de inovar. O enfoque está centrado nos resultados da implementação de uma ou mais inovações. Dos três tipos de aplicação, essa é a que menos observamos na educação, por outro lado, é uma das mais utilizadas em empresas de marketing e gestão;

2) Como metodologia para solução de problemas: O DT se apresenta como "metodologia adequada para a educação porque propõe a solução de problemas a partir da prática da empatia, a qual coloca as pessoas envolvidas no centro do processo e dentro do contexto em que ocorre a situação desafiadora" (CAVALCANTI; FILATRO, 2016, p. 61);

3) Como estratégia de ensino e aprendizagem: Nessa aplicação o DT tem sido apontado como um "ingrediente alternativo, que quebra a rigidez de abordagens pedagógicas centradas no ensino transmissivo" (CAVALCANTI; FILATRO, 2016, p. 65). O DT como estratégia de ensino e aprendizagem permite que estudantes trabalhem em grupos e, de forma criativa, projetem soluções para problemas reais, identificados em um contexto específico.

O DT pode ser adotado como uma ATA uma vez que, em suas etapas, grupos de estudantes têm a possibilidade de não só propor soluções para um problema identificado como também de prototipá-las, fazendo uso das TDIC. O DT tem muito a contribuir na educação por estimular que a resolução de problemas, a inovação e a adoção de estratégias de ensino e aprendizagem centradas nos estudantes, promovendo maior significado e efetividade as práticas pedagógicas e considerando as TDIC, torna-se uma poderosa estratégia com a ATA.

Por ser mais complexo na sua realização no campo educacional, trabalhos envolvendo o DT na educação ainda são escassos, principalmente quando envolve as tecnologias. Em nossa busca no corpus latente, apenas um trabalho em língua portuguesa envolvia a química. Este trabalho descreve o processo de elicitação e documentação de requisitos para ambientes virtuais de aprendizagem móvel (SOUZA; SILVA, 2014). A ação foi baseada nos conceitos do DT, provocando as necessidades dos clientes, produzindo protótipos rápidos e simples que eventualmente convergem para soluções inovadoras. As autoras seguiram os passos proposto pela Ideo (2013), considerando a imersão, ideação e prototipagem, além de enfatizaram que é "necessário um número razoável de participantes para que possamos encontrar propostas interessantes" (SOUZA; SILVA, 2014, p. 13). É mister destacar que no DT para obter bons resultados, quanto mais propostas são realizadas na etapa de brainstorm (ideação), mais

\begin{tabular}{l|l|l|l|l|l}
\hline ( ) Rev. Inter. Educ. Sup. & Campinas, SP & v.4 & n.3 & p.580-609 & set./dez. 2018
\end{tabular}


soluções são encontradas, e as tecnologias (baseadas nos princípios da ATA) possibilitam alcançar uma resolução considerada adequada ao problema inicial.

\section{CONSIDERAÇÕES FINAIS}

A incorporação da Aprendizagem Tecnológica Ativa permite que professores e alunos aprofundem os conteúdos de interesse, proporcionando um ganho na aprendizagem em relação à metodologia tradicional, independente da disciplina. A ATA representa um esforço assinalável para explicar como ocorre a incorporação das TDIC às metodologias ativas na Educação. Com efeito, esta tem a seu favor, como foi observado, um acervo considerável de possibilidades de aplicações para promover uma aprendizagem ativa, em flagrante contraste com a passividade ressaltada no modelo de ensino (dito) tradicional.

$\mathrm{Na}$ medida em que vem satisfazer uma necessidade profundamente sentida, esta pesquisa discutiu sobre o modelo da ATA destacando os pilares que influenciam sua abordagem, ao tempo que identifica características e clarifica possibilidades na Educação. Assim, acreditamos que esta pesquisa pode evocar nos professores uma mudança em sua postura e que estes incorporem em sua prática pedagógica a ATA.

Em relação ao levantamento e análise das publicações, esta pesquisa possibilitou identificar alguns trabalhos envolvendo a ATA no Ensino de Química, indicando caminhos para que professores a utilizem na construção do conhecimento de seus alunos. Embora os resultados do corpus latente descritos tenham sido utilizados para o Ensino de Química, este estudo pode servir de modelo para outras áreas que integram tecnologia na sala de aula ou para educadores que buscam incorporar a aprendizagem tecnológica ativa em sua prática docente. É pertinente destacar e compreender os resultados descritos por meio do corpus latente de conteúdo que podem propiciar resultados satisfatórios, não somente nas investigações das Ciências (Química), mas em todas as áreas do conhecimento.

A partir do que foi apresentado nesta pesquisa, é possível compreender a importância da ATA no contexto educacional atual, ainda que muitos docentes se manifestam dizendo preferirem não modificarem sua práxis pedagógica. Assim, ao refletir sobre a ATA, consideramos importante que os professores promovam atividades que valorizem o aprendizado centrado nos alunos, além de proporem estratégias para sua aplicação. Nesse contexto, destaca-se também que devemos utilizar os ambientes baseados na ATA de modo que aprimorem os resultados no processo de ensino e aprendizagem, que forneçam oportunidades para os alunos se envolverem presencial e virtualmente e fomentem conexões uns com os outros. Ademais, observações e dados da pesquisa indicam que o uso das tecnologias pelos alunos possibilita um melhor desempenho dos mesmos em uma aprendizagem tecnológica ativa. 
Por fim, é importante reforçar que o modelo da aprendizagem tecnológica ativa não se contrapõe a outros modelos de aprendizagem, entretanto sua integração no processo de ensino e aprendizagem pode gerar bons resultados. Consideramos que o modelo proposto apresenta uma visão abrangente do uso concomitante das tecnologias digitais e das metodologias ativas na Educação. Investigações futuras e o desenvolvimento de estudos posteriores serão pertinentes para compreender e consequentemente inserir a ATA nos diversos contextos educacionais.

\section{REFERÊNCIAS}

ARAÚJO, José Carlos Souza. Fundamentos da metodologia de ensino ativa (1890-1931). In: REUNIÃO NACIONAL DA ANPEd, 37., 2015, Florianópolis. Anais do... [S.1.]: ANPEd, 2015.

AUSUBEL, David Paul; NOVAK, Joseph; HANESIAN, Helen. Psicologia educacional. Rio de Janeiro: Interamericano, 1980.

BANDURA, Albert. Modificação do comportamento. Rio de Janeiro: Interamericana, 1979.

BARBOSA, Eduardo Fernandes; MOURA, Dácio Guimarães de. Metodologias ativas de aprendizagem na Educação Profissional e Tecnológica. B. Tec. Senac, v. 39, n. 2, p. 48-67, 2013.

BEAUCHAMP, Tom; CHILDRESS, James. Principles of biomedical ethics. New York: Oxford, 1994.

BERGMANN, Jonathan; SAMS, Aron. Sala de Aula Invertida: Uma metodologia Ativa de Aprendizagem. Rio de Janeiro: LTC, 2016.

BONWELL, Charles; EISON, James. Active learning: creating excitement in classroom. 1. ed. Washington: The George Washington University, School of Education and Human Development, 1991.

BRADLEY, Eizabeth; CURRY, Leslie; DEVERS, Kelly. Qualitative data analysis for health services research: Developing taxonomy, themes, and theory. Health Research and Education Trust, v. 42, n. 4, p. 1758-1772, 2007.

BRASIL. Ministério da Educação. Secretaria da Educação Média e Tecnológica. Parâmetros Curriculares Nacionais - Ciências da Natureza e suas Tecnologias. Brasília: MEC, 2002.

BROWN, Tim. Change by Design: How Design Thinking Transforms Organizations and Inspires Innovation, New York: HarperBusiness, 2009.

BRUNER, Jerome. Uma nova teoria da aprendizagem. Rio de Janeiro: Bloch, 1976 
CAVALCANTI, Caroline Costa; FILATRO, Andrea. Design thinking na educação presencial, a distância e corporativa. São Paulo: Saraiva, 2016.

CHAPARRO, Rebeca Piumbato. Sala de Aula Invertida: uma alternativa para a aprendizagem de modelos atômicos no Ensino Médio. In: $5^{\circ}$ CONGRESSO DE PESQUISA E ENSINO, 2016, São Paulo. Anais do... São Paulo: [s.n.] 2016.

COOREY, Jillian. Active Learning Methods and Technology: Strategies for Design

Education. International Journal of Art \& Design Education, v. 35, n. 3, p. 337-347, 2016.

CORMIER, Caroline; VOISARD, Bruno. Flipped Classroom in Organic Chemistry Has Significant Effect on Students' Grades. Frontiers in ICT, v. 4, p. 1-15, 2018.

CROUCH, Catherine; MAZUR, Eric. Peer instruction: Ten years of experience and results. American journal of physics, v. 69, n. 9, p. 970-977, 2001.

D.SCHOOL. Bootcamp Bootleg. Palo Alto: Hasso Plattner Institute of Design at Stanford, p. 1-44, 2011. Disponível em: <https://goo.gl/3nFmMa〉. Acesso em: 12 fev. 2018.

DALE, Edgard. Audiovisiual methods in teaching. $3^{\text {a }}$ Ed. New York: Holt, Reinhart \& Winston, 1969.

DEMO, Pedro. Formação Permanente e tecnologias educacionais. Petrópolis, RJ: Vozes. 2006.

DEWEY, John. Vida e educação. São Paulo: Nacional, 1950

FLEURY, Maria Tereza Leme; FLEURY, Afonso. Construindo o conceito de competência. Revista de administração contemporânea, v. 5, n. SPE, p. 183-196, 2001.

FREIRE, Paulo. Pedagogia da autonomia: saberes necessários à prática educativa. 27. ed. São Paulo: Paz e Terra, 1996.

GAETA, Cecília; MASETTO, Marcos. Metodologias ativas e o processo de aprendizagem na perspectiva da inovação. In: PBL 2010 CONGRESSO INTERNACIONAL, 2010, São Paulo. Anais do... São Paulo, 2010.

GOLDE, Michael; MCCREARY, Christine; KOESKE, Randi. Peer Instruction in the General Chemistry Laboratory: Assessment of Student Learning. Journal of Chemical Education, v. 83, n. 5, p. 804-810, 2006.

HOFFMANN, Jussara. Avaliação mediadora: uma prática em construção da pré-escola à universidade. 33 ed. Porto Alegre: Mediação, 2014.

HORN, Michael; STAKER, Heather. Blended: usando a inovação disruptiva para aprimorar a educação. Porto Alegre: Penso, 2015. 
HOUAISS, Dicionário Eletrônico. São Paulo: Editora Objetiva, 2001.

IDEO. Design Thinking para Educadores. Traduzido por Instituto Educadigital. 2013. Disponível em: <http://www.dtparaeducadores.org.br>. Acesso em: 16 mar. 2018.

IDEO. HCD Toolkit. Palo Alto: Ideo, 2009. Disponível em <https://goo.gl/uf8aia>. Acesso em: 10 fev. 2018.

KELLY, Rhea. 2017 Teaching with technology survey. Campus Technology, v. 30, n.7, 2017.

LEITE, Bruno Silva. Discussões sobre Ambientes Pessoais de Aprendizagem. Revista EducaOnline, v.10, n.1, p. 37-54, 2016.

LEITE, Bruno Silva. Gamificando as aulas de química: uma análise prospectiva das propostas de licenciandos em química. RENOTE, v. 15, n. 2, p. 1-10, 2017a.

LEITE, Bruno Silva. Sala de aula invertida: uma análise das contribuições e de perspectivas para o Ensino de Química. Enseñanza de las ciencias, n. Extra, p. 1591-1596, 2017 b.

LEITE, Bruno Silva. Tecnologias no Ensino de Química: teoria e prática na formação docente. $1^{\text {a }}$ Ed. Curitiba: Appris, 2015.

LIMA-JÚNIOR, Cláudio Gabriel et al. Sala de Aula Invertida no Ensino de Química: Planejamento, Aplicação e Avaliação no Ensino Médio. Revista Debates em Ensino de Química, v. 3, n. 2, p. 119-145, 2017.

LÜDKE, Menga; ANDRÉ, Marli. Abordagens qualitativas de pesquisa: a pesquisa etnográfica e o estudo de caso. São Paulo: EPU, 1986.

MARTÍN, Alfredo Prieto. Flipped Learning: Aplicar el modelo de aprendizaje inverso. Madrid: Narcea, 2017.

MASTERS, Ken. Edgar Dale's Pyramid of Learning in medical education: A literature review. Medical teacher, v. 35, n. 11, p. e1584-e1593, 2013.

MCWHINNEY, William. Isolating organizational dynamics in a small group experiment. Sociometry, v. 26, p. 354-372, 1963.

MELO, Lina; SÁNCHEZ, Ramiro. Análisis de las percepciones de los alumnos sobre la metodología flipped classroom para la enseñanza de técnicas avanzadas en laboratorios de análisis de residuos de medicamentos veterinarios y contaminantes. Educación Química, v. 28, n. 1, p. 30-37, 2017.

MEYERS, Chet; JONES, Thomas. Promoting Active Learning. San Francisco: Jossey-Bass Publishers, 1993. 
MITRE, Sandra Minardi et al. Metodologias ativas de ensino-aprendizagem na formação profissional em saúde: debates atuais. Ciência \& saúde coletiva, v. 13, n. 2, p. 2133-2144, 2008.

MOORING, Suazette; MITCHELL, Chloe; BURROWS, Nikita. Evaluation of a flipped, large-enrollment organic chemistry course on student attitude and achievement. Journal of Chemical Education, v. 93, n. 12, p. 1972-1983, 2016.

MORAES, Luiza Dumont de Miranda; CARVALHO, Regina Simplício; NEVES, Álvaro José Magalhães. O Peer Instruction como proposta de metodologia ativa no ensino de química. Journal of Chemical Engineering and Chemistry, v.2, n.3, p.107-131, 2016.

OECD. "Brazil", in Education at a Glance 2014: OECD Indicators. Paris: OECD Publishing, 2014. Disponível em: <http://dx.doi.org/10.1787/eag-2014-en〉. Acesso em 15 mar. 2018.

OECD. Education at a Glance 2017: OECD Indicators. Paris: OECD Publishing, 2017. Disponível em: <http://dx.doi.org/10.1787/eag-2017-en〉. Acesso em: 19 mar. 2018.

ONRUBIA, Javier; COLOMINA, Rosa; ENGEL, Anna. Os ambientes virtuais de aprendizagem baseados no trabalho em grupo e na aprendizagem colaborativa. In: COLL, César; MONEREO, Carles. (Org.). Psicologia da educação virtual: aprender e ensinar com as tecnologias da informação e da comunicação. Porto Alegre: Artmed, 2010. p. 208-225.

PAIVA, Marlla Rúbya Ferreira et al. Metodologias ativas de ensino-aprendizagem: revisão integrativa. SANARE-Revista de Políticas Públicas, v. 15, n. 2, p. 145-153, 2016.

PAPERT, Seymour. Constructionism: A new opportunity for elementary science education. Massachusetts Institute of Technology, Media Laboratory, Epistemology and Learning Group, 1986.

PIAGET, Jean. Psicologia e pedagogia. Rio de Janeiro: Forense Universitária, 2006.

PINA, Antonio Ramón Bartolomé; SOUZA, Francislê Neri; LEÃO, Marcelo Brito Carneiro. Investigación Educativa a Partir de La Información Latente en Internet. Revista Eletrônica de Educação, v. 7, n. 2, p. 301-316, 2013.

REIS, Dayr Américo dos. Estrutura de organização e comportamento de aprendizagem.

Revista de Administração de Empresas, v. 15, n. 2, p. 07-16, 1975.

REIS, Rafaela da Silva; LEITE, Bruno Silva; LEÃO, Marcelo Brito Carneiro. Apropriação das Tecnologias da Informação e Comunicação no ensino de ciências: uma revisão sistemática da última década (2007-2016). RENOTE, v. 15, n. 2, p. 1-10, 2017.

ROCHA, Henrique Martins; LEMOS, Washington de Macedo. Metodologias ativas: do que estamos falando? Base conceitual e relato de pesquisa em andamento. In: IX Simpósio

\begin{tabular}{|l|c|c|c|c|c|}
\hline C) Rev. Inter. Educ. Sup. & Campinas, SP & v.4 & n.3 & p.580-609 & set./dez. 2018 \\
\hline
\end{tabular}


Pedagógico e Pesquisas em Comunicação. Resende, Brasil. Anais do... São Paulo: Associação Educacional Dom Boston, p. 12, 2014.

ROGERS, Carl. Liberdade para aprender. Belo Horizonte: Interlivros, 1973.

ROMANCINI, Richard. Colin Lankshear e Michele Knobel: Aprendizagem social. Comunicação \& educação, n.1, p. 91-103, 2015.

RYAN, Michel; REID, Scott. Impact of the flipped classroom on student performance and retention: A parallel controlled study in general chemistry. Journal of Chemical Education, v. 93, n. 1, p. 13-23, 2016.

SANTAELLA, Lucia. A aprendizagem ubíqua na educação aberta. Revista Tempos e Espaços em Educação, v. 7, n. 14, p. 15-22, 2014.

SANTOS, Anderson Oliveira et al. Dificuldades e motivações de aprendizagem em Química de alunos do ensino médio investigadas em ações do (PIBID/UFS/Química). Scientia Plena, v. 9, n. 7, p. 1-6, 2013.

SCHULTZ, David et al. Effects of the flipped classroom model on student performance for advanced placement high school chemistry students. Journal of chemical education, v. 91, n. 9, p. 1334-1339, 2014.

SEERY, Michael. Flipped learning in higher education chemistry: emerging trends and potential directions. Chemistry Education Research and Practice, v. 16, n. 4, p. 758-768, 2015.

SELWYN, Neil. Educação e Tecnologia: questões críticas. In: FERREIRA, Giselle Martins dos Santos; ROSADO, Luiz Alexandre da Silva; CARVALHO, Jaciara de Sá. (Org.).

Educação e Tecnologia: abordagens críticas. Rio de Janeiro: SESES, 2017. p. 85-103.

SIEMENS, George. Connectivism: A Learning Theory for the Digital Age. Instructional Technology and Distance Education, v. 2, n.1, p. 3-10, 2004.

SILBERMAN, Mel. Active learning: 101 strategies do teach any subject. Massachusetts: Allyn and Bacon, 1996.

SOUZA, Cynara Lira de Carvalho; SILVA, Carla. Uso do design thinking na elicitação de requisitos de ambientes virtuais de aprendizagem móvel. In: WER. 2014.

SOUZA, Francislê Neri de. Internet: Florestas de dados ainda por explorar. Internet Latent Corpus Journal, v.1, n. 1, p. 2-4, 2010.

SOUZA, Jéssica Itaiane Ramos de; LEITE, Quesia dos Santos Souza; LEITE, Bruno Silva. Avaliação das dificuldades dos ingressos no curso de licenciatura em Química no sertão pernambucano. Revista Docência do Ensino Superior, v. 5, n. 1, p. 135-159, 2015.

\begin{tabular}{|l|c|c|c|c|c|}
\hline C) Rev. Inter. Educ. Sup. & Campinas, SP & v.4 & n.3 & p.580-609 & set./dez. 2018 \\
\hline
\end{tabular}


THIOLLENT, Michel. Metodologia da pesquisa-ação. São Paulo: Cortez, 2005.

TOFFLER, Alvin. A terceira onda. 29. ed. Rio de Janeiro: Record, 2007.

TOLEDO, Luiza Helena Lellis Andrade de Sá Sodero; LAGE, Fernanda de Carvalho. O Peer Instruction e as Metodologias Ativas de Aprendizagem: relatos de uma experiência no Curso de Direito. Anais do... XXII ENCONTRO NACIONAL DO CONPEDI/UNINOVE, p. 375390, 2013.

VALENTE, José Armando; ALMEIDA, Maria Elizabeth Bianconcini de; GERALDINI, Alexandra Flogi Serpa. Metodologias ativas: das concepções às práticas em distintos níveis de ensino. Revista Diálogo Educacional, v. 17, n. 52, p. 455-478, 2017.

VYGOTSKY, Lev. A formação social da mente: o desenvolvimento dos processos psicológicos superiores. São Paulo: Martins Fontes, 1998.

YAHYA, Saadiah; AHMAD, Erny Arniza; JALIL, Kamarularifin Abd. The definition and characteristics of ubiquitous learning: A discussion. International Journal of Education and Development using Information and Communication Technology, v. 6, n. 1, p. 117$127,2010$.

YESTREBSKY, Cherie. Flipping the classroom in a large chemistry class-research university environment. Procedia-Social and Behavioral Sciences, v. 191, p. 1113-1118, 2015.

\section{Sobre o autor \\ ${ }^{1}$ Bruno Silva Leite $\mathbb{D}$ \\ E-mail: leitebrunosilva@gmail.com \\ Universidade Federal Rural de Pernambuco - Brasil \\ Doutor em Química pela Universidade Federal de Pernambuco [UFPE].}

